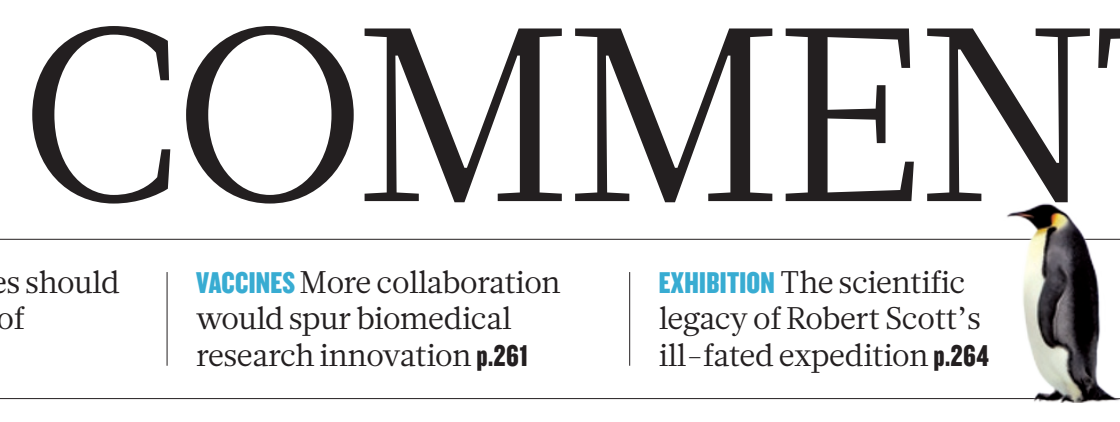

OBITUARY Paul Doty,

PHILANTHROPY Charities should pay their fair share of research costs $\mathbf{p . 2 6 0}$ would spur biomedical

research innovation $\mathbf{p . 2 6 1}$ legacy of Robert Scott's ill-fated expedition $\mathbf{p . 2 6 4}$ chemist and arms-control advocate $\mathbf{p . 2 6 6}$

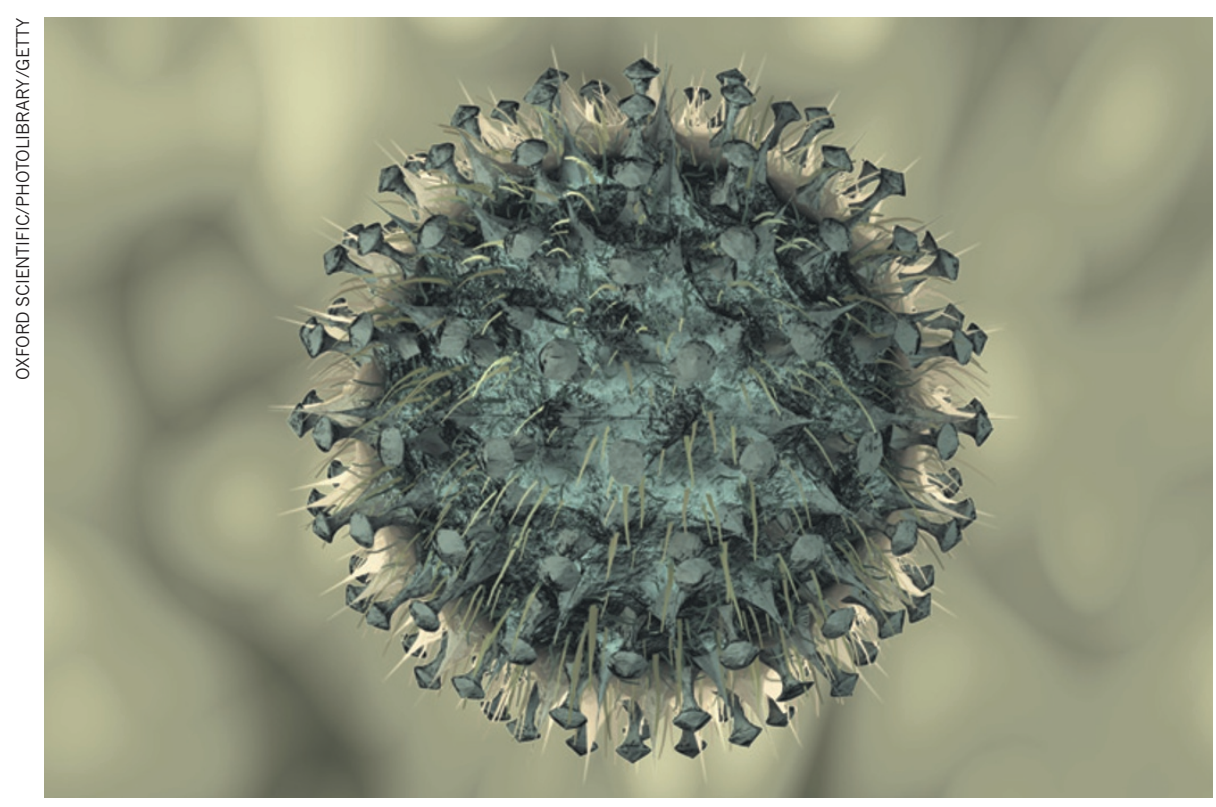

\title{
The fight over flu
}

\section{A proposal to restrict the planned publication of} research on a potentially deadly avian influenza virus is causing a furore. Ten experts suggest ways to proceed.

\section{RON FOUCHIER \& AB OSTERHAUS Globalize the discussion}

\section{Erasmus MC, Rotterdam, the Netherlands}

So far, most of the human deaths from the deadly H5N1 strain of bird flu have occurred in Asia and the Middle East. Many labs worldwide - including ours - are trying to understand what makes the virus so virulent, and how to stop it. H5N1 research is thus a global issue, yet the entire research community seems to be following the advice of one country.

We are not questioning the unprecedented recommendations last month from the US
National Science Advisory Board for Biosecurity (NSABB) to remove key details from the methods and results sections of published papers, including our own, submitted to Science (see Nature 481, 9-10; 2012). But we do question whether it is appropriate to have one country dominate a discussion that has an impact on scientists and public-health officials worldwide. This discussion should include the perspective of people in regions where $\mathrm{H} 5 \mathrm{~N} 1$ has infected humans. Will the NSABB also advise on which international researchers and officials have the right to see the full papers, to help implement urgently needed surveillance and other intervention strategies?

It is not clear whether an international discussion would lead to different recommendations. There is no global equivalent of the NSABB, but many European experts that we have seen quoted in the press believe that the research should be published in full.
We don't know the worldwide opinion until a group of experts from all parts of the globe is formed. An issue this big should not be decided by one country, but by all of us.

\section{JOHN STEINBRUNER A system for redacted papers}

Director, Center for International and Security Studies at Maryland, University of Maryland, College Park

If the two papers (submitted to Nature and Science) describing a transmissible form of the $\mathrm{H} 5 \mathrm{~N} 1$ virus are the first to be published with key details missing, they probably won't be the last. We need to establish both a shortterm and a long-term solution for how the scientific community should handle such a publication. Who decides who should have access to the full details? Who monitors the community so that the details don't get passed around outside the group of experts cleared to receive them?

I believe that the entire process must be regulated by a global health body, ideally the World Health Organization (WHO). Already, a WHO committee oversees all research involving the smallpox virus. A similar, more developed system could work for H5N1 and other deadly pathogens. An international group of experts would approve research involving those agents, decide who will have access to the details of papers that come out of that work, and hold those vetted individuals accountable for what they do with the information. For instance, such a system might allow permitted experts to view papers only electronically, so nothing is on paper. A database could record the privileged few people who have seen the full paper, and what they do with the information. In all likelihood, legal safeguards would be needed to protect the rights of people who receive the sensitive information. Such a process would not offer complete protection against misuse, but it would show the scientific community that the committee is watching what they do.

Because dangerous pathogens are a global issue, any procedure would need buy-in $>$ 


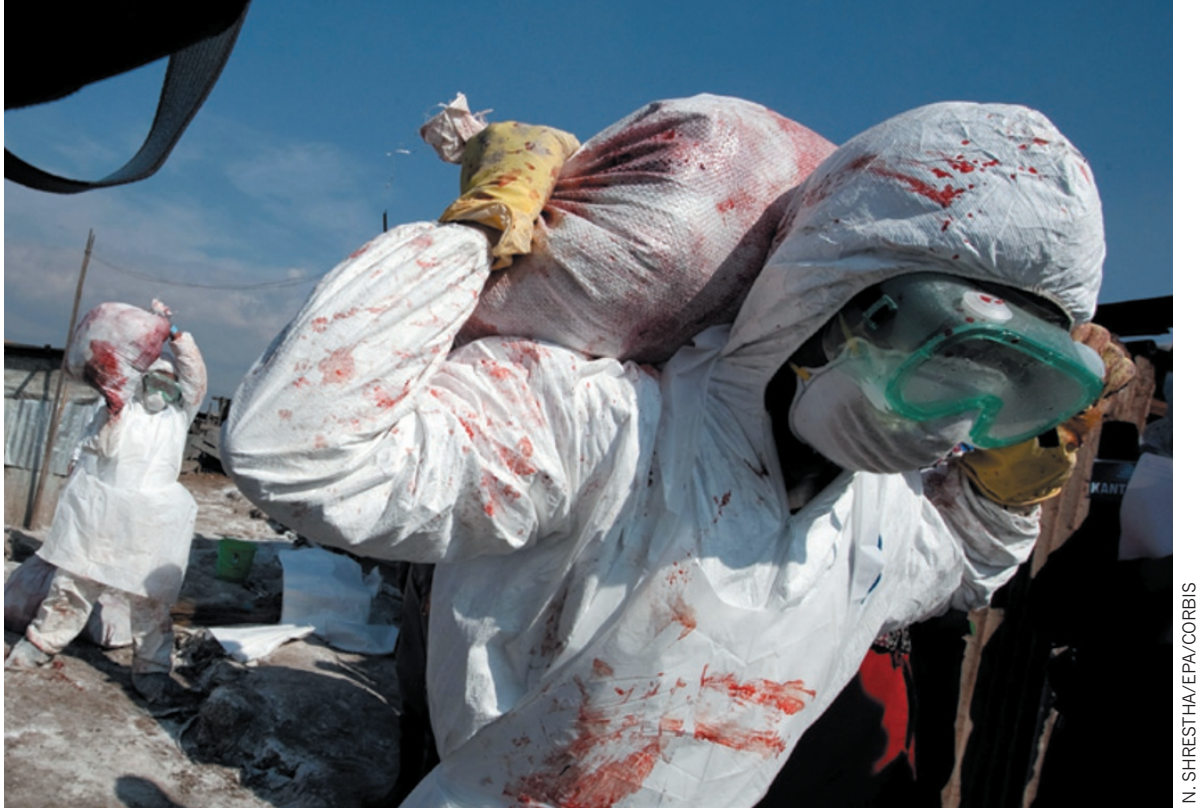

could save millions of people in the case of a natural pandemic. If national-security organizations become involved, they will vet scientists on the basis of citizenship, and will be inclined to discriminate against those countries in which terrorists have found refuge. But some of those countries are among the few that have experienced human deaths from $\mathrm{H} 5 \mathrm{~N} 1$, and are most likely to witness the origins of a natural pandemic. It is crucial that scientists and other experts are judged on their qualifications, not on their nationality. If the world is to accept the process, national-security officials cannot be allowed to dominate the discussion.

KWOK-YUNG YUEN

\title{
The Hong Kong perspective
}

\author{
Chair of Infectious Disease, \\ Department of Microbiology, \\ University of Hong Kong
}

As a scientist working in Hong Kong - the site of the first human epidemic of infection by the highly fatal H5N1 virus - I appreciate the public-health significance of knowing which mutations confer airborne transmissibility in an animal model. The new, muchdebated research provides this information. Finding similar genomic signatures in animal or human viruses collected from the WHO Global Influenza Surveillance Network may alert public-health workers to an impending epidemic of unthinkable magnitude or severity. But I also appreciate the possibility that such mutants could cause a global disaster if accidentally or deliberately produced and released into animal and human populations. Consequently, I support the recommendation from the NSABB to remove key details from the papers describing this work.

Biological warfare is familiar to people living in this part of the world. During the Sino-Japanese War in the 1930s and 1940s, scientists and physicians of the Japanese

South Asian countries such as Nepal are among the most likely to be hit by avian flu epidemics.

army's Unit 731 infected civilians and prisoners of war in Manchuria, China, with Yersinia pestis, the bacterium behind the Black Death, which was first identified in plague patients in Hong Kong in 1894. When the unit found that the bacteria caused severe organ damage when serially inoculated into prisoners of war, the unit began spreading plague-contaminated fleas in China, causing outbreaks.

Censoring scientific data for publication will not stop rogue individuals or nations from developing a deadly and highly transmissible form of $\mathrm{H} 5 \mathrm{~N} 1$, but it would at least buy some time to find and stockpile the appropriate antivirals, immunomodulators and vaccines to protect against most variants of H5N1. Even if the publications omit the methods for making such a deadly virus, the genomic signatures associated with airborne transmissibility should be known to the directors of all public-health laboratories in the WHO surveillance network, after they sign an agreement of confidentiality.

\section{A. HENDERSON The ultimate biological threat}

\section{Center for Biosecurity, University of Pittsburgh Medical Center, Pennsylvania}

The H5N1 influenza strain poses a potential biological hazard far more serious than any we have ever known. It is a virus that is capable of killing half its victims, a proportion greater than that for any other epidemic disease. Were that coupled with the transmissibility of a pandemic flu virus, it would have characteristics of an ultimate biological weapon unknown even in science fiction (see Nature 480, 421-422; 2011). We should not publish a blueprint for constructing such an organism.
LYNN KLOTZ\& ED SYLVESTER Worry about
lab infections

Center for Arms Control and

Non-Proliferation, Washington DC; Walter Cronkite School of Journalism at Arizona State University

Asian bird flu is just one of the extremely dangerous pathogens researched in laboratories throughout the world. Along with the two labs that created a potentially contagious form of $\mathrm{H} 5 \mathrm{~N} 1$, at least 40 others worldwide investigate deadly, highly contagious pathogens not currently present in human populations, such as the SARS virus and the recently resurrected 1918 pandemic flu virus. Public-health experts worry about natural pandemics, and governments worry about the risk that these pathogens pose to national security - but the probability of accidental release is likely to be much higher.

We have analysed the likelihood of escape from 42 labs, using $1 \%$ as the estimated probability of an escape from a single lab in a single year. This approximates the historical probability, obtained by dividing the documented number of escapes of these pathogens ( 3 , each involving the SARS virus) by our estimate of the total number of lab-years of research on these pathogens since 2003 (more than 300 lab years). Lab infections can easily spread: in 2004, after the only natural SARS outbreak in humans was contained, two graduate students labinfected with SARS in Beijing infected seven others, causing one death.

Our analysis shows that the probability of an escape from at least one of 42 labs in a single year is $34 \%$; within less than 4 years, 
the chance of escape reaches $80 \%$. If more labs begin studying the (potentially) human contagious form of $\mathrm{H} 5 \mathrm{~N} 1$, that interval will decrease even further.

In comparison, the average time between the three natural influenza pandemics in the last century was about 30 years (1918, 1957 and 1968). We are creating a risk that is much greater than that posed by nature. Laboratories need stronger precautions, such as mandatory quarantine of lab staff working on live dangerous pathogens until they can be certified clear of infection. Regulators should not be sitting idly by, while the threat of a man-made pandemic looms.

JEFFERYK. TAUBENBERGER Study how viruses swap hosts

Chief, Viral Pathogenesis and Evolution Section, Laboratory of Infectious

Diseases, US National Institute of Allergy and Infectious Diseases

How influenza viruses adapt to humans and cause disease has been a significant interest of my laboratory, including sequencing the genome of the $1918 \mathrm{H} 1 \mathrm{~N} 1$ influenza, the virus that caused the worst pandemic on record. This work has led to research on how influenza viruses switch hosts and cause severe disease, and is serving as a basis for new vaccines and therapies. As a result of these studies, scientists and public-health officials are better prepared to prevent or mitigate a similar future pandemic. Studies examining adaptation and transmission of avian H5N1 influenza virus are similarly important.

For reasons not yet clear, some influenza viruses adapted to poultry can acquire sets of mutations that kill almost every bird that they infect, but rarely infect humans. Since 1997, H5N1 viruses have devastated poultry flocks in southeast Asia and other parts of the world, and also caused disease in a limited number of the presumably tens of thousands of humans who have had direct contact with infected birds. Although human infections are uncommon, the high fatality rate in those people infected by $\mathrm{H} 5 \mathrm{~N} 1$ more than $50 \%$ - raises serious concerns.

A growing body of evidence suggests that influenza host-switching processes are complex, and may be unique to each virus. Changes in the $1918 \mathrm{H} 1 \mathrm{~N} 1$ virus crucial for adapting to humans, for example, were not found in the 2009 pandemic $\mathrm{H} 1 \mathrm{~N} 1$ virus. It is essential to continue research into this with $\mathrm{H} 5 \mathrm{~N} 1$ and other emerging pathogens, and to investigate how they adapt and cause disease. The work could provide better surveillance tools to detect viruses that are in the process of adapting to humans. Scientists must be able to continue to work with these viruses safely and appropriately, in multiple teams utilizing the talents of many researchers, and under the numerous layers of protection and oversight that safeguard scientists and the public.

Of course, scientists will have to continuously re-examine and discuss the balance between the benefits of conducting and publishing pathogen research, and the risk of misuse of such knowledge. We should continue the dialogue as we continue the research.

RICHARD H. EBRIGHT
Mitigate the
risks of release

Department of Chemistry and

Chemical Biology, Rutgers

University, Piscataway, New Jersey

Engineered derivatives of highly pathogenic avian influenza virus capable of aerosol transmission in non-rodent mammals pose potential threats to human health and to food production. The major concern is accidental release, for example through infection of a lab worker who then infects others. Deliberate release by a disturbed or disgruntled lab worker, bioterrorism and biowarfare are also concerns.

The following steps should be taken immediately. To address accidental release, assign the viruses as pathogens that require the highest biosafety level ('level 4', not 'level 3+' as has been the case to date). To address deliberate release, assign the viruses as pathogens that require the highest level of biosecurity ('Tier 1', like smallpox virus and anthrax bacterium, under the revised US select-agent rule that enters into force this year).

To minimize risks from future research, additional steps should be taken. We need to implement a system of mandatory prior review of research directed at increasing a pathogen's virulence, transmissibility or ability to evade countermeasures. We also need to re-evaluate, and preferably terminate, biodefence expenditures on research directed at creating and assessing new biothreats, as opposed to addressing existing biothreats. Creating and assessing new threats rarely increases security. Doing so in biology where the number of potential threats is nearly infinite, and where the asymmetry between the ease of creating threats and the difficulty of addressing threats is nearly absolute - is especially counterproductive.
DAVID L. HEYMANN

We will always need vaccines

\author{
Head, Centre on Global Health \\ Security, Chatham House, London
}

The creation in vitro of highly transmissible forms of $\mathrm{H} 5 \mathrm{~N} 1$ is a fresh reminder of how the endgame in infectious-disease control has changed.

For years, scientists and officials have believed that the ultimate application of disease control was eradication. In a world free from a particular pathogen, the disease no longer occurs, and the expense - and small risk - of vaccination is avoided. As a result, there would be no need to develop and maintain vaccine stockpiles. This idea began to change in 2002, when the poliovirus was synthesized de novo. The change has been profound - the endgame must now take into consideration the possibility that consolidation and safe storage, or destruction, of remaining polioviruses is not sufficient to eliminate the risk that it will be reintroduced. With the possibility of synthesizing a virus, it is likely that we will always need to have vaccines readily available.

But some say that maintaining samples of deadly pathogens is a necessary precaution. Take the discussions about the samples of smallpox virus (Variola), maintained at two WHO-sanctioned laboratories since the virus's eradication. Some now argue that we need these samples to study the virus, and to develop new vaccines and therapies in case of a bioterrorist attack. Indeed, the WHO Advisory Group of Independent Experts that reviews the smallpox research programme noted this year that DNA sequencing, cloning and gene synthesis could now allow de novo synthesis of the entire Variola virus genome and creation of a live virus, using publicly available sequence information, at a cost of about US $\$ 200,000$ or less.

It is tempting to argue that, for the sake of public health, research that constructs highly pathogenic forms of viruses, such as H5N1, should be squashed. But even if we eliminated $\mathrm{H} 5 \mathrm{~N} 1$ and destroyed all lab samples, we would still need to consider keeping and producing a vaccine, because the virus could potentially be recreated. And stopping this type of research would open a dangerous door. Although adding and deleting genes can create super-strains that put the entire world at risk, such research also helps to develop public-health tools such as vaccines and diagnostic tests. Preventing this research would also prevent us from using all possible scientific options to prepare for naturally occurring or deliberately caused - outbreaks. 